This item was submitted to Loughborough's Research Repository by the author.

Items in Figshare are protected by copyright, with all rights reserved, unless otherwise indicated.

\title{
A switched reluctance motor torque ripple reduction strategy with deadbeat current control
}

PLEASE CITE THE PUBLISHED VERSION

\section{PUBLISHER}

\section{IEEE}

\section{VERSION}

AM (Accepted Manuscript)

\section{PUBLISHER STATEMENT}

(C) 2019 IEEE. Personal use of this material is permitted. Permission from IEEE must be obtained for all other uses, in any current or future media, including reprinting/republishing this material for advertising or promotional purposes, creating new collective works, for resale or redistribution to servers or lists, or reuse of any copyrighted component of this work in other works.

\section{LICENCE}

All Rights Reserved

\section{REPOSITORY RECORD}

Ma, Mingyao, Qingqing Yang, Xing Zhang, Fei Li, and Zhengyu Lin. 2019. "A Switched Reluctance Motor Torque Ripple Reduction Strategy with Deadbeat Current Control”. figshare. https://hdl.handle.net/2134/38219. 


\section{A Switched Reluctance Motor Torque Ripple Reduction Strategy with Deadbeat Current Control}

\author{
Mingyao Ma \\ School of Electrical Engineering and \\ Automation \\ Hefei University of Technology \\ Hefei, China \\ miyama@hfut.edu.cn \\ Fei Li \\ School of Electrical Engineering and \\ Automation \\ Hefei University of Technology \\ Hefei, China \\ sandflylf@qq.com
}

\author{
Qingqing Yang \\ School of Electrical Engineering and \\ Automation \\ Hefei University of Technology \\ Hefei, China \\ yangqingqing5066@163.com \\ Zhengyu Lin \\ School of Mechanical, Electrical and \\ Manufacturing Engineering \\ Loughborough University \\ Leicestershire, United Kingdom \\ z.lin@ieee.org
}

\author{
Xing Zhang \\ School of Electrical Engineering and \\ Automation \\ Hefei University of Technology \\ Hefei, China \\ hongLf@ustc.edu.cn
}

\begin{abstract}
This paper presents a switched reluctance motor (SRM) torque ripple reduction strategy with deadbeat current control. In this method, the SRM torque is indirectly controlled by the phase current. The deadbeat control method can predict the duty cycle of the switching signal for the next control period according to current error, and achieve an accurate current tracking. Thus, SRM torque control error can be reduced significantly. The feasibility and effectiveness of the proposed strategy have been verified in both simulation and experimental studies.
\end{abstract}

Keywords-switched reluctance motor (SRM), deadbeat control, predict the duty cycle, torque ripple reduction

\section{INTRODUCTION}

Over the last two decades, electric vehicles (EVs) and hybrid electric vehicles (HEVs) have attracted increasing attention ${ }^{[1]-[3]}$. Permanent magnet (PM) motor is one of the most popular electric motors in applications of EVs/HEVs, but has potential issues for mass production due to the scarcity of rare-earth materials ${ }^{[4]}$. In addition, permanent magnet materials will suffer from magnetic deterioration under high temperature, vibration and overcurrent conditions, which will damage the motor seriously and affect the safe operation of EVs/HEVs.

Switched reluctance motors (SRM) have attracted more and more attention for research and industrial applications, due to the advantages of rare-earth-free feature, high efficiency, robust structure, excellent fault tolerance operation, high starting torque for initial acceleration, and so on $^{[5]-[11]}$. Consequently, SRMS have been considered as a promising candidate for EVs /HEVs applications. At present, SRMs have been used in some EVs/HEVs on the market, such as Holden's ECOmmodore and Xiamen Jinlong's XMQ6125G hybrid city bus, etc. However, because of double-saliency structure of SRMs, high torque ripples and noise are the inherent issues caused by normal force fluctuations during phase current excitations ${ }^{[12]-[13]}$, which limits SRMs in the EVs/HEVs applications with high performance requirements. Thus, SRM torque ripple reduction techniques are necessary for EVs/HEVs applications. At high speed range, the angle interval position of the conduction interval is the core factor for determining the SRM output performance. Therefor angle position control method is usually used to reduce torque ripple. To reduce torque ripple at low speed range, various schemes have been proposed in recent years ${ }^{[14]-[18]}$, and direct instantaneous torque control (DITC) and torque-sharing function (TSF) are two common solutions. DITC has advantage of simple structure, but it requires complex switching rules for smoothing torque ripples during the commutation period ${ }^{[19]}$.

TSF based torque ripple reduction methods have advantages of simple control structure and easy implementation $^{[20]-[21]}$. Several TSF methods have been reported, such as linear, cubic, and exponential TSFs, and can be implemented offline or online $e^{[19],[22]-[25]}$. In [19], a nonlinear logical TSF for torque ripple reduction and efficiency enhancement is introduced. In [22] and [23], an iterative learning controller is proposed to add a compensation current to the current reference to reduce the torque ripple resulting from the nonlinearity of an SRM. In [24], turn-on angle of an adaptive TSF is adjusted with the speed in order to reduce torque ripple. In [25], the shape of proposed TSF is flexible, and not limited to a specific type. The objective function of the proposed TSFs directly combines the squares of the phase current and derivatives of current reference with a Tikhonov factor.

Most of the TSFs mentioned above implement torque control by phase current control, which require accurate phase current controllers. Hysteresis current controller (HCC) is a simple way to track the nonlinear current reference. When implemented with micro-controller, it has a good control performance with high switching frequency. However, in the high-power applications, the switching frequency is limited by the comprehensive factors such as the switching power loss and reliability of the switch device. It is difficult to implement high performance current control under HCC with the limited switching frequency.

Deadbeat control methods have been used to track the torque and flux linkage of $\mathrm{SRM}^{[26]}$. In this paper, a novel deadbeat current control method integrated into the SRM phase current controller, which can improve the current control accuracy with the limited switching frequency for 
high-power SRM drive systems. The deadbeat control method can predict the duty cycle of the switching signal for the next control period according to current error, and achieve an accurate current tracking. Thus, the method can reduce the SRM torque ripple for TSF based torque ripple reduction methods. In order to validate the feasibility and effectiveness of the proposed control method, the simulation and experimental validations have carried out on a threephase 12/8-pole $35 \mathrm{~kW} \mathrm{SRM.}$

\section{TORQUE SHARING FUNCTION CONTROL OF SWITCHED RELUCTANCE MOTOR}

Fig. 1 shows the block diagram of the torque sharing function control of an SRM, which is mainly composed of an SRM, a power converter, and a TSF control module. Each module of the system will be described in detail below.

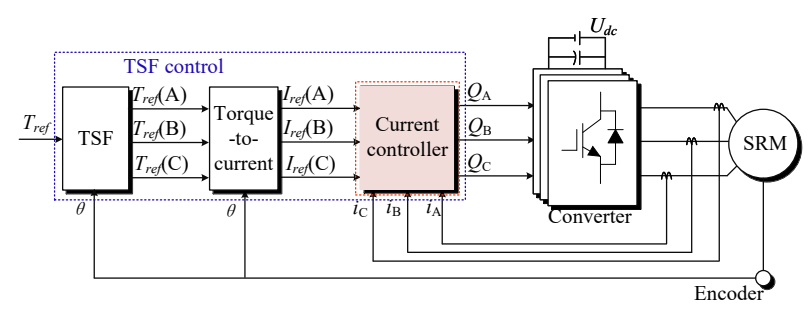

Fig.1. Block diagram of torque sharing function control of switched reluctance motor

\section{A. Power converter}

Power converter is an important part of the system. Asymmetric half-bridge converters are commonly used for SRM drive systems, as shown in Fig. 2. Each phase has two main switches and two freewheeling diodes.

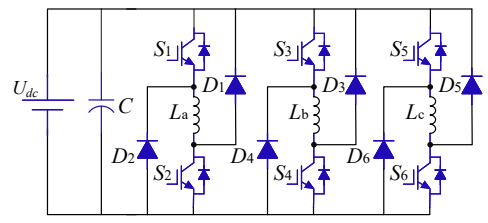

Fig.2. Topology of an asymmetric bridge inverter

As shown in Fig.3, when the two main switches of a phase winding are both on, the power is supplied to this phase windings, the voltage of the winding is bus voltage $U_{d c}$, and the state is $S=1$. When the upside switch is off and the downside switch is on, the current flows through a diode and the applied voltage of the windings is 0 , this state is $S=0$. When the two main switches are both off, the phase current flows through the two diodes and the applied voltage of the windings is $-U_{d c}$, this state is $\mathrm{S}=-1$.

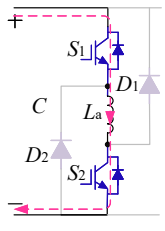

$\mathrm{S}=1$

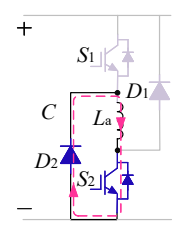

$\mathrm{S}=0$

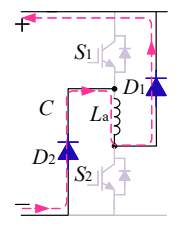

$\mathrm{S}=-1$
Fig.3 States of energized winding

\section{B. TSF control module}

The SRM total output torque is composed of the sum of the torque generated by all phases at the same time. In order to produce a torque with low ripples, the total torque reference can be divided into individual phase torque references through TSF, as shown in (1). The reference torque of each phase can be obtained by (2).

$$
f_{\mathrm{M}}(\theta)= \begin{cases}0 & 0 \leq \theta \leq \theta_{\text {on }} \\ f_{\text {rise }}(\theta) & \theta_{\text {on }} \leq \theta \leq \theta_{\text {on }}+\theta_{\text {overlap }} \\ 1 & \theta_{\text {on }}+\theta_{\text {overlap }} \leq \theta \leq \theta_{\text {off }}-\theta_{\text {overlap }} \\ f_{\text {fall }}(\theta) & \theta_{\text {off }}-\theta_{\text {overlap }} \leq \theta \leq \theta_{\text {off }} \\ 0 & \theta_{\text {off }} \leq \theta \leq \theta_{p} \\ & T_{\text {ref }}(\mathrm{M})=T_{\text {ref }} * f_{\mathrm{M}}(\theta)\end{cases}
$$

where $T_{\text {ref }}$ is the total torque reference, $T_{\text {ref }}(\mathrm{M})$ is the torque reference for Mth phase; $\theta$ is the rotor position; $f_{\mathrm{M}}(\theta)$ is the Mth phase TSF, $f_{\text {rise }}(\theta)$ is the rising TSF for the incoming phase, $f_{\text {fall }}(\theta)$ is the decreasing TSF for the outgoing phase; $\theta_{\text {on }}$, $\theta_{\text {off }}, \theta_{\text {overlap }}$ and $\theta_{p}$ are turn-on angle, turn-off angle, overlapping angle, and rotor pole pitch, respectively.

Linear and sinusoidal TSF methods are commonly used. The linear TSF has constant slope of torque in the commutation region. This method is simple, but it cannot reflect nonlinear torque production characteristics of SRM. Therefore, the torque ripple is increased around the beginning and end of commutation due to the higher nonlinear inductance slope. The sinusoidal TSF uses a sinusoidal curve during commutation, and it is more suitable in a nonlinear system compared to the linear TSF. Thus, the sinusoidal TSF is adopted in this paper, as shown in Fig. 4.

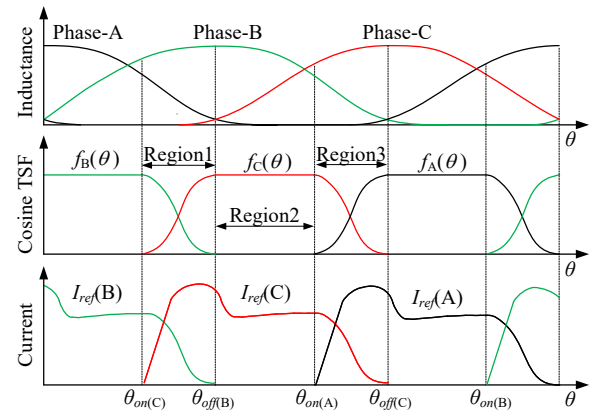

Fig.4. Phase inductances, sine TSF and phase current reference curves

In TSF control module, the input total torque reference Tref is divided into individual torque references for each phase through TSF block with respect to rotor position. The separate torque references are converted to current references in the "Torque-to-current" block based on rotor position information. In traditional control method, a phase current controller $\mathrm{HCC}$ is used to track these current references.

\section{A DEADBEAT CONTROL METHOD}

For high-power applications, the power switching frequency is limited to reduce the switching power loss. In order to improve the SRM current control accuracy at low switching frequency conditions, a deadbeat current control method is proposed in this research.

\section{A. Working principle of deadbeat control method}

The deadbeat current control method is shown in Fig. 5. 


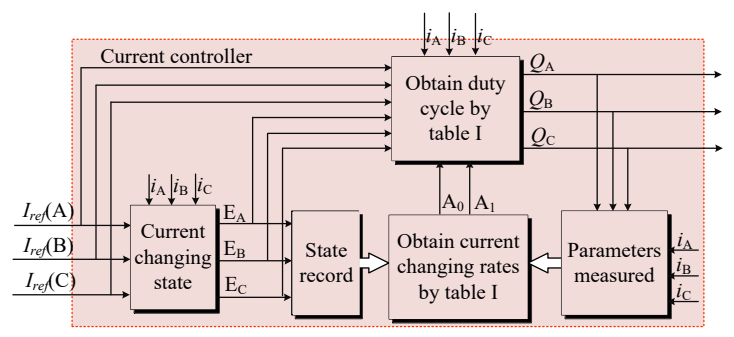

Fig.5. The deadbeat current control method

By neglecting mutual coupling phase, the phase voltage equation of an SRM can be given as

$$
U=r \cdot i+\frac{d \psi(\theta, i)}{d t}
$$

where $U$ is the voltage applied to the phase winding, $r$ is the resistance of the winding, $i$ is the current of phase, $\Psi$ is the linkage flux.

The flux linkage is determined as function of inductance and current phase

$$
\psi(\theta, i)=L(\theta, i) \cdot i
$$

By incorporating (4) in (3), we obtain

$$
\begin{aligned}
& U=r \cdot i+\frac{d[L(\theta, i) \cdot i]}{d t} \\
& =r \cdot i+i \cdot \frac{d[L(\theta, i)]}{d t}+L(\theta, i) \cdot \frac{d i}{d t}
\end{aligned}
$$

In digital drive system, because switching period is very short, an assumption is made that phase inductance remains unchanged in a switching period. Thus, (5) can be expressed as

$$
U=r \cdot i+L(\theta, i) \cdot \frac{d i}{d t}
$$

According to (6), changing rate of the phase current can be obtained as

$$
\frac{d i}{d t}=\frac{U-r \cdot i}{L(\theta, i)}
$$

When the freewheeling state is applied to the phase winding, the changing rate of the phase current can be expressed as (8).

$$
\mathrm{A}_{0}=-\frac{r \cdot i}{L(\theta, i)}
$$

Because in this state, the phase current change slowly, $\mathrm{A}_{0}$ can be assumed to remain constant over a switching period.

When the phase voltage is bus voltage Udc or negative bus voltage $-U_{d c}$, the voltage of $r$ can be ignored. Thus, the changing rates of the phase current can be expressed as

$$
\mathrm{A}_{1}=\frac{U_{d c}}{L(\theta, i)} \approx-\mathrm{A}_{2}
$$

where $A_{1}$ and $A_{2}$ are the changing rates of the phase current, when the phase voltage is $U_{d c}$ and $-U_{d c}$, respectively.

The working principle of the deadbeat control method is shown in Fig. 6. The following assumptions has been made for the design of the deadbeat control:
- The SRM speed is constant in a continuous three electric cycle, because the acceleration of SRM is limited by its inertia.

- Turn-on angle and turn-off of each phase are the same in a continuous three electric cycle, respectively.

Based on the above assumptions, online measured SRM running parameters of previous two phases can be used for the phase current control, and predict the required duty cycle of pulse width modulation (PWM) for the next switching period accurately.

For example, running parameters measured when phase $\mathrm{A}$ and $\mathrm{B}$ were excited can be used for the current control for phase C.

In order to achieve the required changing rates of phase current, the linear equation G1 is obtained from the (10) according to the running parameters of phase A. Meanwhile, the linear equation G2 is obtained from the (11) according to the running parameters of phase $\mathrm{B}$. Then the linear equations G1 and G2 are combined and solved to obtain the changing rates of phase current $\mathrm{A}_{0}(k+1)$ and $\mathrm{A}_{1}(k+1)$. Equations (10) and (11) are shown below.

$\left\{\begin{array}{l}\frac{\mathrm{A}_{1}(k+1) \cdot q_{\mathrm{A}}(k+1)}{f}-\frac{\mathrm{A}_{0}(k+1) \cdot\left(1-q_{\mathrm{A}}(k+1)\right)}{f}=\Delta i_{\mathrm{A}}(k+1), \text { if } \mathrm{E}_{\mathrm{A}}(k+1)=1 \\ -\frac{\mathrm{A}_{1}(k+1) \cdot\left(1-q_{\mathrm{A}}(k+1)\right)}{f}-\frac{\mathrm{A}_{0}(k+1) \cdot q_{\mathrm{A}}(k+1)}{f}=\Delta i_{\mathrm{A}}(k+1), \text { if } \mathrm{E}_{\mathrm{A}}(k+1)=-1\end{array}\right.$

$\left\{\begin{array}{l}\frac{\mathrm{A}_{1}(k+1) \cdot q_{\mathrm{B}}(k+1)}{f}-\frac{\mathrm{A}_{0}(k+1) \cdot\left(1-q_{\mathrm{B}}(k+1)\right)}{f}=\Delta i_{\mathrm{B}}(k+1), \quad \text { if } \mathrm{E}_{\mathrm{B}}(k+1)=1 \\ -\frac{\mathrm{A}_{1}(k+1) \cdot\left(1-q_{\mathrm{B}}(k+1)\right)}{f}-\frac{\mathrm{A}_{0}(k+1) \cdot q_{\mathrm{B}}(k+1)}{f}=\Delta i_{\mathrm{B}}(k+1), \text { if } \mathrm{E}_{\mathrm{B}}(k+1)=-1\end{array}\right.$

where $q_{\mathrm{A}}(k+1), \triangle i_{\mathrm{A}}(k+1)$ and $\mathrm{E}_{\mathrm{A}}(k+1)$ are duty cycle, current variation and current changing state in the of phase $A$ electric cycle, respectively. $q_{\mathrm{B}}(k+1), \triangle i_{\mathrm{B}}(k+1)$ and $\mathrm{E}_{\mathrm{B}}(k+1)$ are duty cycle, current variation and current changing state in the of phase B electric cycle, respectively. The current changing state of " 1 " indicates that the overall trend of the phase current is rising in the corresponding switching period. The current changing state of "- 1 " indicates that the overall trend of phase current is reduced in the corresponding switching period.

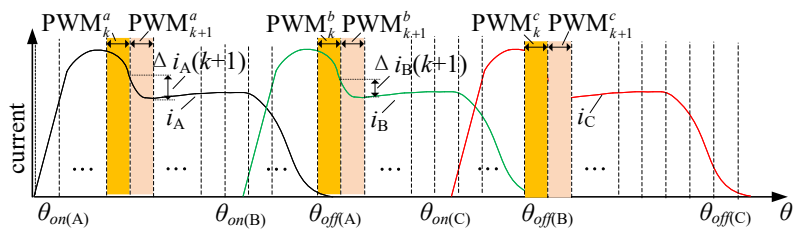

Fig.6. Control principle of deadbeat control method

Then, the phase $\mathrm{C}$ current changing state $\mathrm{E}_{\mathrm{C}}(k+1)$ can be calculated using (12). The duty cycle $q_{\mathrm{C}}$ of the next switching period is obtained using (13).

$$
\left\{\begin{array}{l}
\mathrm{E}_{c}(k+1)=1, \text { if } I_{r e f}(k+1)+\frac{\mathrm{A}_{0}(k+1)}{f} \geq i_{c} \\
\mathrm{E}_{c}(k+1)=-1, \text { if } I_{r e f}(k+1)+\frac{\mathrm{A}_{0}(k+1)}{f}<i_{c}
\end{array}\right.
$$

- The SRM's three phases are identical. 


$$
\left\{\begin{array}{l}
\frac{\mathrm{A}_{1}(k+1) \cdot q_{\mathrm{C}}(k+1)}{f}-\frac{\mathrm{A}_{0}(k+1) \cdot\left(1-q_{\mathrm{C}}(k+1)\right)}{f}=I_{r e f}(k+1)-i_{\mathrm{C}}, \quad \text { if } \mathrm{E}_{c}(k+1)=1 \\
-\frac{\mathrm{A}_{1}(k+1) \cdot\left(1-q_{\mathrm{C}}(k+1)\right)}{f}-\frac{\mathrm{A}_{0}(k+1) \cdot q_{\mathrm{C}}(k+1)}{f}=I_{r e f}(k+1)-i_{\mathrm{C}}, \text { if } \mathrm{E}_{c}(k+1)=-1
\end{array}\right.
$$

\section{B. Digital realization of the deadbeat control method}

Taking the phase $\mathrm{C}$ current control as an example, the digital implementation of the proposed deadbeat control method is explained.

Firstly, the conducting phase is decided according to the position feedback of SRM.

Secondly, duty cycle, current variation and current changing state in $(k+1)$ th switching period have been recorded for previous phase A and phase B current control. According to the values of $\mathrm{E}_{\mathrm{A}}(k+1)$ and $\mathrm{E}_{\mathrm{B}}(k+1)$, there are four combinatorial states: $(1,1),(1,-1),(-1,1)$ and $(-1,-1)$. According to these combinatorial states, the changing rates of phase $\mathrm{C}$ current are achieved with equations in table I .

Then, the current changing state $\mathrm{E}_{\mathrm{C}}(k+1)$ in the next switching period can be calculated with (13). According to

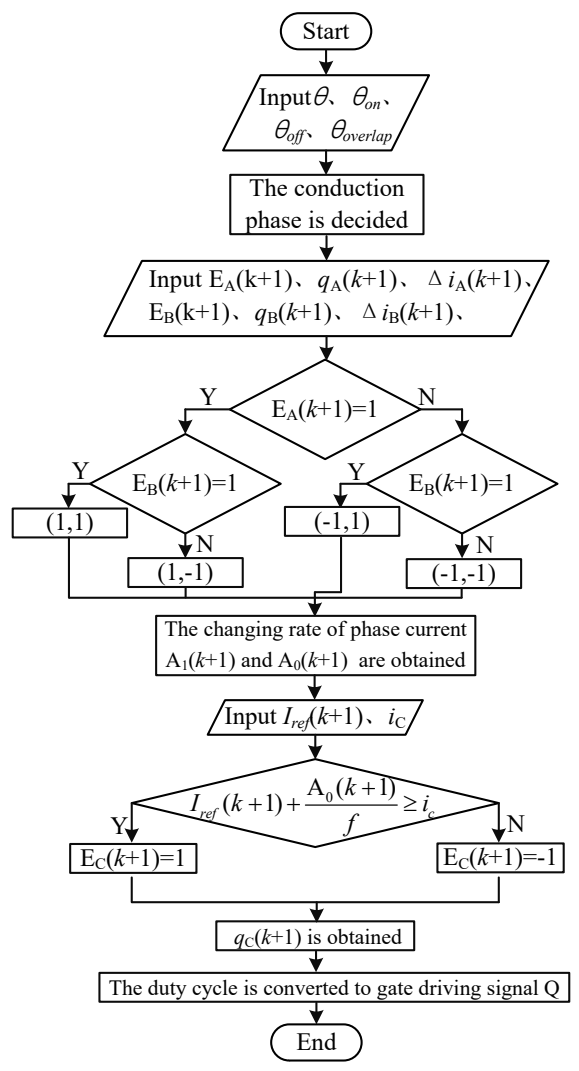

Fig.7. The flow chart of the digital implementation of the deadbeat control method

the current changing state $\mathrm{E}_{\mathrm{C}}(k+1)$, the duty cycle $\mathrm{q}_{\mathrm{C}}$ of the next switching period is obtained with equations in table I .

Finally, the duty cycle $\mathrm{q}_{\mathrm{C}}$ is converted to gate drive signal $\mathrm{Q}$ for the power convertor.

The flow chart of the deadbeat control method is shown in Fig. 7, and these equations used in the flow chart are shown in the table I.
TABLE I. EQUATIONS USED IN THE FLOW CHART

\begin{tabular}{|c|c|}
\hline State & Equation \\
\hline$(1,1)$ & $\begin{array}{l}\mathrm{A}_{0}(k+1)={ }^{\Delta} \quad \frac{q_{\mathrm{B}}(k+1)-\Delta i_{\mathrm{B}}(k+1) \cdot q_{\mathrm{A}}(k+1)}{q_{\mathrm{A}}(k+1)-q_{\mathrm{B}}(k+1)} \cdot f \\
\mathrm{~A}_{1}(k+1)=\frac{\Delta i_{\mathrm{B}}(k+1) \cdot f+\mathrm{A}_{0}\left(1-q_{\mathrm{B}}(k+1)\right)}{q_{\mathrm{B}}(k+1)}\end{array}$ \\
\hline$(1,-1)$ & $\left\{\begin{array}{l}\mathrm{A}_{0}(k+1)=\frac{\Delta i_{\mathrm{A}}(k+1) \cdot\left(1-q_{\mathrm{B}}(k+1)\right)+\Delta i_{\mathrm{B}}(k+1) \cdot q_{\mathrm{A}}(k+1)}{-\left[\left(1-q_{\mathrm{A}}(k+1)\right) \cdot\left(1-q_{\mathrm{B}}(k+1)\right)+q_{\mathrm{A}}(k+1) \cdot q_{\mathrm{B}}(k+1)\right]} \cdot f \\
\mathrm{~A}_{1}(k+1)=\frac{\Delta i_{\mathrm{B}}(k+1) \cdot f+\mathrm{A}_{0} \cdot q_{\mathrm{B}}(k+1)}{q_{\mathrm{B}}(k+1)-1}\end{array}\right.$ \\
\hline$(-1,1)$ & $\begin{array}{l}\mathrm{A}_{0}(k+1)=\frac{\left[\Delta i_{\mathrm{A}}(k+1) \cdot q_{\mathrm{B}}(k+1)+\Delta i_{\mathrm{B}}(k+1) \cdot\left(1-q_{\mathrm{A}}(k+1)\right)\right] \cdot f}{-\left[\left(1-q_{\mathrm{A}}(k+1)\right) \cdot\left(1-q_{\mathrm{B}}(k+1)\right)+q_{\mathrm{A}}(k+1) \cdot q_{\mathrm{B}}(k+1)\right]} \\
\mathrm{A}_{1}(k+1)=\frac{\Delta i_{\mathrm{B}}(k+1) \cdot f+\mathrm{A}_{0} \cdot\left(1-q_{\mathrm{B}}(k+1)\right)}{q_{\mathrm{B}}(k+1)}\end{array}$ \\
\hline$(-1,-1)$ & $\begin{array}{l}\mathrm{A}_{0}(k+1)=\left[\begin{array}{l}\Delta \quad \frac{\left.\left(1-q_{\mathrm{B}}(k+1)\right)-\Delta i_{\mathrm{B}}(k+1) \cdot\left(1-q_{\mathrm{A}}(k+1)\right)\right] \cdot f}{q_{\mathrm{B}}(k+1)-q_{\mathrm{A}}(k+1)} \\
\mathrm{A}_{1}(k+1)=\frac{\Delta i_{\mathrm{B}}(k+1) \cdot f+\mathrm{A}_{0} \cdot q_{\mathrm{B}}(k+1)}{\left(q_{\mathrm{B}}(k+1)-1\right)}\end{array}\right.\end{array}$ \\
\hline $\mathrm{E}_{\mathrm{C}}(k+1)=1$ & $q_{\mathrm{C}}(k+1)=\frac{I_{r e f}(k+1) \cdot f-i_{\mathrm{C}}+\mathrm{A}_{0}(k+1)}{\mathrm{A}_{1}(k+1)+\mathrm{A}_{0}(k+1)}$ \\
\hline $\mathrm{E}_{\mathrm{C}}(k+1)=-1$ & $q_{\mathrm{C}}(k+1)=\frac{\left(I_{r e f}(k+1)-i_{\mathrm{C}}\right) \cdot f+\mathrm{A}_{1}(k+1)}{\mathrm{A}_{1}(k+1)-\mathrm{A}_{0}(k+1)}$ \\
\hline
\end{tabular}

\section{SIMULATION VERIFICATION}

To verify that the proposed control method can improve the comfort and safety of the high-power digital SRM drive system in EVs/HEVs applications, the proposed TSF based torque ripple reduction algorithm for an SRM drive system is implemented in MATLAB/SIMULINK.

The simulation parameters of the SRM are the same as the SRM parameters of the experimental platform, as shown in table II. A three-phase asymmetric half bridge power converter as shown in Fig. 2 is used.

\section{ABLE II. SRM AND DRAG MOTOR PARAMETERS}

\begin{tabular}{ccc}
\hline Parameters & $\begin{array}{c}\text { Value for the } \\
12 / 8 \text { SRM }\end{array}$ & $\begin{array}{c}\text { Value for the tow } \\
\text { permanent magnet } \\
\text { motor }\end{array}$ \\
\hline Phase number & 3 & 3 \\
Rated power $P_{\mathrm{e}} / \mathrm{kW}$ & 35 & 50 \\
Maximum power $P_{\mathrm{e}} / \mathrm{kW}$ & 60 & 100 \\
Rated voltage $U_{\mathrm{e}} / \mathrm{V}$ & 336 & 336 \\
Rated current $I_{\mathrm{e}} / \mathrm{A}$ & 115 & 140 \\
Rated speed $n_{\mathrm{e}}(\mathrm{rpm})$ & 2000 & 1500 \\
Stator/rotor poles & $12 / 8$ & $/$ \\
Type of cooling & Air cooling & Water cooling
\end{tabular}

In the simulations, the total torque reference is set as $60 \mathrm{Nm}$. The SRM drive system works at $9.6 \mathrm{kHz}$. In the simulation results, ia and UA are phase current and phase voltage of phase A. T and Tavg are total instantaneous output torque and total average output torque. The torque ripple is defined as

$$
T_{\text {rip }}=\frac{T_{\max }-T_{\min }}{T_{\text {avg }}}
$$

where $T_{\max }$ and $T_{\min }$ are the maximum torque and minimum torque. 
Fig. 8 shows the simulation waveforms of phase current, phase voltage, total instantaneous output torque and total average output torque at 500rpm. Fig. 8(a) is the simulation result without the proposed deadbeat current control, and the torque ripple is $50.3 \%$. Fig. 8 (b) is the simulation results with the proposed deadbeat current control method for TSF, and the torque ripple is reduced to $24 \%$ because of accurate current tracking.

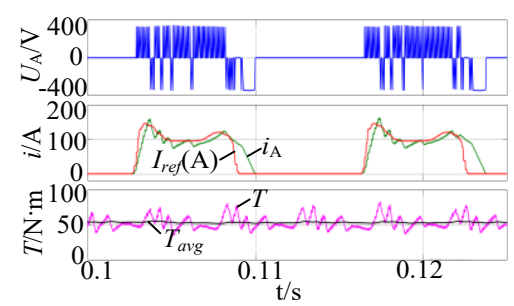

(a) TSF control without deadbeat current control

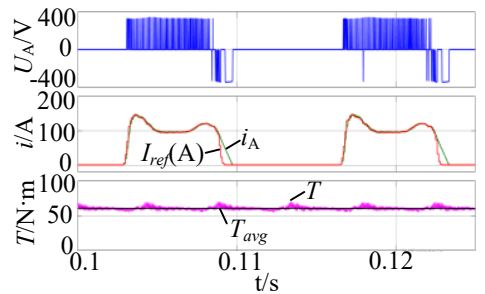

(b) The deadbeat control method for TSF

Fig. 8 Simulation results for low-speed ( $\mathrm{n}=500 \mathrm{rpm}$ )

Fig. 9 shows the simulation results at a higher motor speed of 2000rpm. Similar conclusion as Fig. 8 can be obtained.

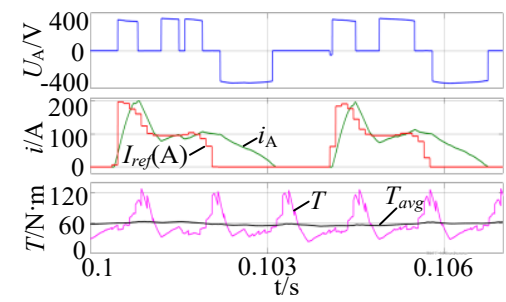

(a) TSF control without deadbeat current control

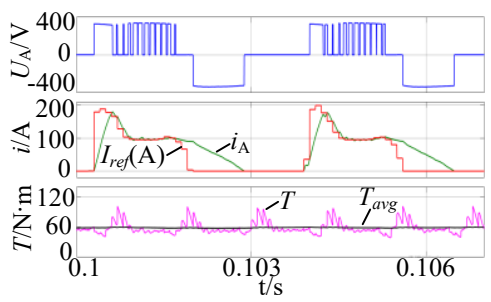

(b) The deadbeat control method for TSF

Fig.9 Simulation results for rated speed $(\mathrm{n}=2000 \mathrm{rpm})$

From Fig. 8 and Fig. 9, it can be found that the proposed deadbeat current control based TSF method can improve the SRM phase current control accuracy and reduce SRM torque control error significantly.

\section{EXPERIMENTAL RESULT}

In order to validate the feasibility and effectiveness of the proposed control method experimentally, an experimental system has been setup with the SRM parameters as shown in table II.
The experimental system is shown in Fig. 10. The proposed control methods are implemented in a Texas Instruments (TI)'s TMS320F28335DSP control board, and the current and voltage are observed using current clamp 700924 and voltage clamp 701930 of YOKOGAWA, respectively. The torque of SRM output is measured by torque meter JN338 from Beijing three crystal Joint Technology company with sampling frequency of $5 \mathrm{kHz}-15$ $\mathrm{kHz}$. The real-time torque of SRM output can be sampled online. The instantaneous torque waveforms of SRM are shown by the recorder DL850 from YOKOGAWA combined with the frequency acquisition module 701281. The tow motor is operated in constant speed mode during the experiment. The torque waveforms shown in the experimental results have slight difference to the simulation results. It is because of the sampling frequency limitation of torque sensors, the high frequency components of the torque ripples can not be measured in experiments.

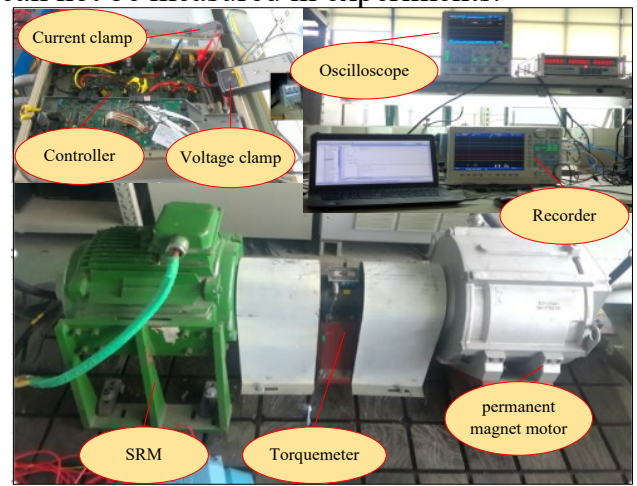

Fig.10 Experimental setup

In the experiment, the parameters such as turn-on angle, turn-off angle, overlapping angle were optimized, and the results of torque tracking at different speeds were obtained. The switching frequency is consistent with simulation model. At speed of $500 \mathrm{rpm}$, the experimental waveforms are shown in Fig. 11.

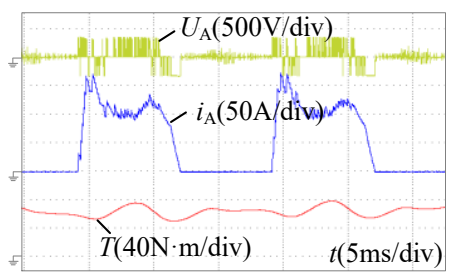

(a) TSF control without deadbeat current control

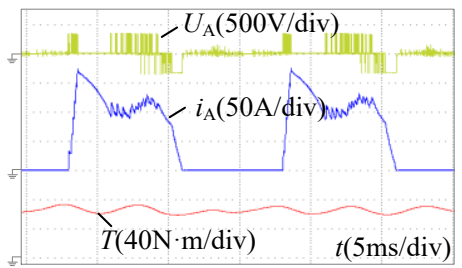

(b) The deadbeat control method for TSF

Fig.11 Experimental results for low-speed $(\mathrm{n}=500 \mathrm{rpm})$

In Fig. 11(a), the traditional TSF control method is applied, and the torque ripple is $50.3 \%$. In Fig. 11(b), the deadbeat control method for TSF is applied, and the torque ripple is $24 \%$. It shows that the proposed method can reduce the torque ripple of SRM significantly and improve the comfort of EVs/HEVs at low speed. 
In the same way, in order to prove that the proposed method can obviously reduce the torque ripple of SRM at rated speed, experimental results are shown in Fig. 12 at $2000 \mathrm{rpm}$.

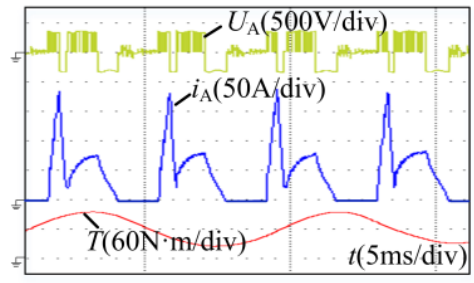

(a) TSF control without deadbeat current control

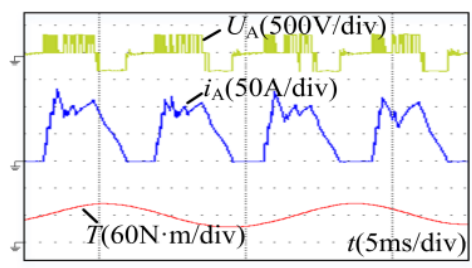

(b) The deadbeat control method for TSF

Fig.12 Experimental results for rated-speed and normal switching frequency operation $(\mathrm{n}=2000 \mathrm{rpm}, \mathrm{f}=9.6 \mathrm{kHz})$

Fig. 12(a), the traditional TSF control method is applied, and the torque ripple is $115 \%$. In Fig. 12(b), the deadbeat control method for TSF is applied, and the torque ripple is reduced to $85 \%$. Thus, it validated that the proposed method can reduce the torque ripple of SRM and improve the comfort of EVs/HEVs at rated speed.

\section{CONCLUSIONS}

This paper presented a switched reluctance motor torque ripple reduction strategy with deadbeat current control. The working principle and digital realization of the proposed method have been introduced in detail. Additionally, the simulation results and experimental results are presented. It can be concluded that the proposed method can improve the SRM current control accuracy, so that SRM torque control error can be reduced significantly.

\section{ACKNOWLEDGMENT}

This paper is supported by National Key R\&D Program of China under Grant No. 2017YFE0112400.

\section{REFERENCES}

[1] B. Ji, X. Song, W. Cao, V. Pickert, Y. Hu, J. W. Mackersie, and G. Pierce, "In situ diagnostics and prognostics of solder fatigue in IGBT modules for electric vehicle drives," IEEE Trans. Power Electron., vol. 30, no. 3, pp. 1535-1543, Mar. 2015.

[2] Y. S. Lai., W. T. Lee, Y. K. Lin, and J. F. Tsai, "Integrated inverter/converter circuit and control technique of motor drives with dualmode control for EV/HEV applications," IEEE Trans. Power Electron., vol. 29, no. 3, pp. 1358-1365, Mar. 2014.

[3] P. Vithayasrichareon, G. Mills, and I. F. MacGill, "Impact of electric vehicles and solar PV on future generation portfolio investment," IEEE Trans. Sustain. Energy., vol. 6, no. 3, pp. 899-908, Jul. 2015.

[4] A. Chiba, K. Kiyota, N. Hoshi, M. Takemoto, S. Ogasawara, "Development of a rare-earth-free SR motor with high torque density for hybrid vehicles," IEEE Trans. Energy Convers., vol. 30, no. 1, pp.175-182, Mar. 2015.

[5] Zhengyu Lin, Donald S. Reay, Barry W. Williams, and Xiangning He, " Online modeling for switched reluctance motors using B-spline neural networks, " IEEE Trans. Industrial Electron., vol. 54, no. 6, pp.3317-3322, Nov. 2007

[6] X. D. Xue et al., "Optimal control method of motoring operation for SRM drives in electric vehicles," IEEE Trans. Veh. Technol., vol. 59, no. 3, pp. 1191-1204, Mar. 2010.

[7] M. Takeno et al., "Test results and torque improvement of the 50-kW switched reluctance motor designed for hybrid electric vehicles," IEEE Trans. Ind. Appl., vol. 48, no. 4, pp. 1327-1334, Jul./Aug. 2012.

[8] Y. Hu, X. Song, W. Cao, and B. Ji, "New SR drive with integrated charging capacity for plug-in hybrid electric vehicles (PHEVs), IEEE Trans. Ind. Electron., vol. 61, no. 10, pp. 5722-5731, Oct. 2014.

[9] A. Chiba et al., "Torque density and efficiency improvements of a switched reluctance motor without rare-earth material for hybrid vehicles," IEEE Trans. Ind. Appl., vol. 47, no. 3, pp. 1240-1246, May/Jun. 2011.

[10] R. Madhavan and B. G. Fernandes, "Axial flux segmented SRM with a higher number of rotor segments for electric vehicles," IEEE Trans. Energy Convers., vol. 28, no. 1, pp. 203-213, Mar. 2013.

[11] C. Hung-Chun and L. Chang-Ming, "Development of a compact switched-reluctance motor drive for EV propulsion with voltageboosting and PFC charging capabilities," IEEE Trans. Veh. Technol., vol. 58, no. 7, pp. 3198-3215, Sep. 2009.

[12] A. H. Isfahani and B. Fahimi, "Comparison of mechanical vibration between a double-stator switched reluctance machine and a conventional switched reluctance machine," IEEE Trans. Magn., vol. 50, no. 2, Feb. 2014, Art. ID 7007104.

[13] D.-H. Lee, T. H. Pham, and J.-W. Ahn, "Design and operation characteristics of four-two pole high-speed SRM for torque ripple reduction," IEEE Trans. Ind. Electron., vol. 60, no. 9, pp. 3637-3643, Sep. 2013.

[14] D.-H. Lee, Z.-G. Lee, J. Liang, and J.-W. Ahn, "Single-phase SRM drive with torque ripple reduction and power factor correction," IEEE Trans. Ind. Appl., vol. 43, no. 6, pp. 1578-1587, Nov./Dec. 2007.

[15] R. C. Kavanagh, J. M. D. Murphy, and M. G. Egan, "Torque ripple minimization in switched reluctance drives using self-learning techniques," in Proc. IEEE IECON, Oct. 28-Nov. 1, 1991, pp. 289294.

[16] D. S. Schramm, B. W. Williams, and T. C. Green, "Torque ripple reduction of switched reluctance motors by phase current optimal profiling," in Proc. IEEE PESC, Jun. 29-Jul. 3, 1992, pp. 857-860.

[17] S. A. Bortoff, R. R. Kohan, and R. Milman, "Adaptive control of variable reluctance motors: A spline function approach," IEEE Trans. Ind. Electron., vol. 45, no. 3, pp. 433-444, Jun. 1998.

[18] C. H. Choi, S. H. Kim, Y. D. Kim, and K. H. Park, "A new torque control method of a switched reluctance motor using a torque-sharing function," IEEE Trans. Magn., vol. 38, no. 5, pp. 3288-3290, Sep. 2002.

[19] D. H. Lee, Z. G. Lee, and J. W. Ahn, “A simple nonlinear logical torque sharing function for low-torque ripple SR Drive," IEEE Trans. Ind. Electron., vol. 56, no. 8, pp. 3021-3028, Aug. 2009.

[20] I. Husain, "Minimization of torque ripple in SRM drives," IEEE Trans. Ind. Electron., vol. 49, no. 1, pp. 28-39, Feb. 2002.

[21] R. Wallace and D. Taylor, "A balanced commutator for switched reluctance motors to reduce torque ripple," IEEE Trans. Power Electron., vol. 7, no. 4, pp. 617-626, Oct. 1992.

[22] S. K. Sahoo, S. K. Panda, and J. Xu, "Indirect torque control of switched reluctance motors using iterative learning control," IEEE Trans. Power Electron., vol. 20, no. 1, pp. 200-208, Jan. 2005.

[23] S. K. Sahoo, S. K. Panda, and J. Xu, "Iterative learning-based highperformance current controller for switched reluctance motors," IEEE Trans. Energy Convers., vol. 19, no. 3, pp. 491-498, Sep. 2004.

[24] N. Chayopitak, R. Pupadubsin, and K. Tungpimolrut, "An online lowripple torque control of switched reluctance motor for small electric vehicle,” in Proc. Int. Conf. Elect. Mach. Syst., Wuhan, China, 2008, pp. 3327-3332.

[25] Jin Ye, Berker Bilgin, and Ali Emadi, "An offline torque sharing function for torque ripple reduction in switched reluctance motor drives," IEEE Trans. Energy Convers., vol.30, no.2, pp.726-735, Jan. 2015

[26] Hao Wen, and Zaiping Pan, "A Novel Dead-Beat Torque Control of Switched Reluctance Machines," in Proc. IEEE International Conference on Electrical Machines and Systems, Aug. 20-Aug. 23, 2011, pp. 1-5. 